\title{
THE FUTURE OF SPIRITUALITY IN SOCIAL WORK: THE FARTHER REACHES OF HUMAN NURTURE
}

\author{
Edward R. Canda
}

\begin{abstract}
This essay discusses the development of the social work profession in relation to the subject of spirituality and proposes future possibilities and recommendations for innovation. It presents historical trends within four phases leading to the present and beyond. Current trends indicate rapidly increasing quantities of publications and other professional activities about spivituality within a pattern of an ever farther reaching integrative approach that encompasses diverse religious and nonreligious perspectives, academic disciplines, international collabontions, and humanity's relationship with the Earth.
\end{abstract}

Keywords: Spirituality, religion, diversity, transpersonal, bistory, future

\section{INTRODUCTION}

In many religious traditions, telling about the future involves two functions that may or may not be combined: prognostication and prophecy. From Greek root words, prognostication literally means 'to know before'; a prognosticator predicts what will be. Also from Greek, prophecy literally means 'to speak before'; a prophet proclaims what sbould be. These kinds of foretelling set out the organization of this essay.

Regarding prognostication, this essay will present currently emerging trends based on evidence from the social work literature and my experience with the topic during the past 2 decades. Regarding prophecy, this essay will offer recommendations for future work that expands on current trends. Prophecy arises from deeply felt moral, value, and ethical commitments. In both prediction and proclamation, the 'foreteller's' own vantage point and biases influence what is said. So in order to avoid the pretense of objective or absolute truth, this essay is written in the "first person" style of I, me, and my. Use of this style is not meant to imply that my view should set the standard for future work on spirituality in social work. Rather, it emphasizes the limits of my view and invites others to join in dialogue and critique.

In 1969, Abraham Maslow published a groundbreaking essay called "The Farther Reaches of Human Narure." In that essay, he reviewed major trends in the field of psychology's understanding of human nature, identified the limits, and proposed an expansion of view toward the highest human possibilities of creativity and consciousness-beyond the egocentric to the transpersonal. Much of what I will say in this article is informed by a transpersonal perspective on social work (Canda \& Smith, 2001; Robbins, Chatterjee, $\&$ Canda, 1998). The subtitle of my essay is a play on the words of Maslow's essay, since I explore the farther reaches of the social work profession's commitment to promote nurture, well-being, and justice for all people. As the essay proceeds to these 'farther reaches,' it may seem indeed more and more 'far-out' if not 'on the fringe'. However, it is necessary

Edward R. Canda is Professor \& Director of the Ph.D. Program in Social Work, Universiry of Kansas, School of Social Welfare, Lawrence, Kansas 66044-3184.

Copyright $(2005$ Aduances in Social Work Vol. 6 No. 1 (Spring 2005), 97-108 
for future looking innovators to take this risk. Otherwise, the profession remains confined to what is taken for granted in the present.

\section{PROGNOSTICATION}

In order to set a context for emerging directions of work, it is helpful to consider where our profession has come from in its relationship with topics of spirituality and religion. Canda and Furman (1999) and Canda (2002a) have suggested a concise and simplified historical perspective. They suggest that our profession in the United States has moved through three broad overlapping phases and is in the midst of a fourth. The following discussion adapts and expands their view of these phases. This historical revicw is meant only as a helpful heuristic framework; it is an oversimplification of a complex and dynamic worldwide process. One of the most glaring limitations of this review is that it starts from a USA based professional social work outlook.

In phase one, sectarian origins, (colonial period through early twentieth century), many congregational and community based philanthropic activities, the settlement house movement, the Charity Organization Society, the Social Gospel movement, and social welfare institutions and policies that led toward the development of professional social work were strongly influenced by religious sectarian views, especially Christian and Jewish, as well as some nonsectarian humanistic spiritual ideologies (Cnaan, 1999). In addition, Indigenous, African American, and French or Spanish colonial influenced Catholic helping and healing traditions existed prior to, outside of, along with, and sometimes within the prior mentioned predominantly Northern European-American social welfare developments (Canda \& Furman, 1999; Martin \& Martin, 2002; Van Hook, Hugen, \& Aguilar, 2001).

In phase two, professionalization and secularization (1920s to 1970s), social work solidified as a profession. Social work and social welfare education, practice, institutions, and policy became increasingly secularized in the mainstream due to concerns about separation of church and state, inappropriate religious proselycization and judgmentalism as well as optimism about scientific and humanist alternative approaches to human behavior and social problems. Social work education over time increasingly neglected the subjects of spirituality and religion. National curriculum guidelines of the Council on Social Work Education (CSWE) deleted references to these subjects in the 1970s and 1980s. However, religiously based social services, tacir religious ideologies, and community based religious helping traditions continued. Ideas from Asian religions and philosophies began to enter social work literature (e.g. Brandon, 1976). In addition, humanistic and other nonsectarian spiritual perspectives grew within social work, such as humanistic psychology, existentialism, and 12 Step programs (Robbins, Chatterjee, \& Canda, 1998). Some authors called for attention to religion and spirituality, but these generally did not gain wide acceptance (e.g. Spencer, 1956; Towle, 1965).

In phase three, resurgence of interest in spirituality (1980s to mid 1990s), religiously based social services and ideas increased in diversity and were discussed more in the social work literature, such as Buddhism, Christianity, Confucianism, Hinduism, Judaism, Shamanism, Spiritism, and Taoism (Canda, Nakashima, Burgess, Russel, \& Barfield, 2003). Nonsectarian spiritual perspectives such as existentialism, Gandhian social acrivism, and transpersonal theory increased. 
One of the most significant innovations during this time was conceptualization of spirituality for social work purposes that addressed the holistic body-mind-spirit-relational qualities of human beings, encompassed diverse religious and nonreligious spiritual perspectives in a respectful way, and provided guidelines for dealing with spirituality consistent with professional values and ethics (e.g. Canda, 1988; Joseph, 1987; Loewenberg, 1988; Sheridan, Wilmer, \& Atchison, 1994; Siporin, 1985). This approach overcame the concerns of many educators and practitioners that social workers might fall into religiously based biases, exclusivism, judgmentalism, discrimination, and oppression when dealing with spirituality in practice, policy, and education. It provided the beginnings of an orientation for social workers and clients of diverse religious and non religious perspectives to cooperate while honoring their own various religious and nonreligious commirments. It also emphasized that addressing spirituality is consistent with the historical foundations of our profession, the enduring person-environment social work vantage point, the reality of increasing diversification in the Unired States, and the professional mission of promoting dignity, respect, and well-being for all people.

Another significant innovation during this time was the establishment of professional networks and organizations that encouraged information sharing, collaboration and synergy among scholars and practitioners committed to an inclusive approach to spiritual diversity. For example, the Society for Spirituality and Social Work began with informal networking in 1986 and was founded as an organization in 1990. This organization also connected with Christian, Jewish, and other professional religious and nonsectarian spiritual networks and organizations. (See links for this Society and other groups dealing with spiritual diversity in social work at www.socwel.ku.edu/canda, retrieved on February 13, 2005.)

I believe that the establishment of an inclusive approach to spiritual diversity founded in professional values and ethics is a major reason why work on spirituality in our profession has been able to increase rapidly in quantity and quality during the next phase. This trend in social work was parallel to and fueled by similar trends in religious studies, anthropology, medicine, nursing, psychology, pastoral care, and other disciplines. It was also stimulated by increasing interests in spirituality (not always inclusive in nature) within the larger popular culture and political discourse.

The fourth phase brings us to the present. The main distinguishing characteristic of this phase is transcending boundaries, that is, boundaries between spiritual perspectives, academic disciplines, nations, governmental and religious institutions, and between humans and nature. Differences and distinctions remain important; but they are embraced by more encompassing perspectives and farther reaching connecring activities. This is similar to what Wilber refers to as the emergence of an integral or holistic mode of consciousness and culture (Robbins, Chatterjee, \& Canda, 1998; Wilber, 1998). I will discuss this phase and its emerging trends in more detail than the previous phases in order to establish a basis for predictions and recommendations about the future. The main trends of phase four are summarized in Table 1.

I mark transition to the fourth phase at the mid 1990 s because the Council on Social Work Education's curriculum guidelines retumed attention to belief systems, religion, and spirituality in 1995 (Canda \& Furman, 1999). Since the mid 1990s, the numbers 
of publications (including textbooks), courses, conferences, and symposia escalated more quickly (Russel, 1998 and personal communication). Some of the textbooks have created for the first time coherent general frameworks of values, knowledge, and skills for practice with spiritually diverse groups (Bullis, 1996; Canda \& Furman, 1999; Ellor, Netting, \& Thibault, 1999). All the previous trends of dealing with an increasing range of both religious and nonreligious approaches to spirituality grew, including for example deep

TABLE 1. Trends in the Fourth Phase (mid 1990s-present): Transcending Boundaries

1. Rate of research and publication increased significantly.

2. General and context-specific concepts of spirituality and religion refined.

3. Curriculum guidelines, courses, and textbooks about spirituality widely established.

4. Frameworks for spiritually sensitive practice formulated.

5. Range of spiritual diversity significantly expanded.

6. Postmodern perspectives on spirituality increased.

7. Faith-based governmental social policy initiatives formalized.

8. Interdisciplinary collaborations and nerworks established.

9. International collaborarions, networking, and global perspective rapidly increased.

10. Whole Earth perspective introduced.

ecological, range of context specific understandings have been explored (e.g. Canda, 1997; Canda \& Furman, 1999; Canda \& Smith, 2001; Canda, Nakashima, Burgess, Russel, \& Barfield, 2003; Hodge, 2000 \& 2002a; Martin \& Martin, 2002; Nelson-Becker, 2003; Praglin, 2004; Van Hook, Hugen, \& Aguilar, 2001).

During this fourth phase, there has been increased influence from postmodern perspectives on spirituality in social work, such as feminist, social constructionist, deep ecological, post-colonial, and transpersonal (Cowley, 1996; Meinert, Pardeck, \& Murphy, 1998). These postmodern perspectives have challenged social work to extend its inclusive approach to spirituality to all people and nations, with special attention to the oppressed and marginalized, to all beings on the planet, and to the Earth itself as a living being deserving of honor and respect. Social workers are being challenged to address links between environmental destruction, poverty, disproportionate wealth of national elites and so-called developed countries, and oppression of women and people of color (e.g. Besthorn \& Canda, 2002; Coates, 2003).

Interdisciplinary collaborations and formal networks increased, such as the Center on Religion, the Professions, and the Public, established in 2003 (see http://rpp.missouri. edu, retrieved February 13, 2005). Indeed, most current scholarly writing on spirituality in social work draws heavily on empirical and conceptual work of other disciplines. In the social policy arena, the controversial Charitable Choice provisions of the Clinton administrations and the faith-based initiatives of the Bush administrations have been stimulating more governmental funding of and collaborations with religious specific congregations, social service agencies, and community groups (Cnaan, 1999; Gibelman \& Gelman, 2003; Tirrito \& Cascio, 2003; Wineburg, 2001).

Finally, an extremely important distinguishing feature of this phase is the internationalization of work on spirituality in social work (c.g. Banerjee, 1997; Canda, 2002a; Canda \& 
Canda, 1996; Furman, Benson, Grimwood, \& Canda, 2004; Nash \& Stewart, 2002; Parel, Naik, \& Humphries, 1997; Rice, 2002; Zahl, 2003). The first international conference of the Society for Spirituality and Social Work occurred in 2000. The Canadian Association for Spirituality and Social Work was established in 2002 (see http://people.stu.ca/mcnssw/, retrieved February 15,2005 ). International symposia on spirituality, social work, and telated fields expanded at the Inter-University Center in Dubrovnik, Croatia. Networks on spirituality and social work have begun development in South Korea. In 2004, the web based Spirituality and Social Work Resource Center, with a transdisciplinary, international, and interfaith approach to spirituality, social work, and health was established. (This center can be reached via www.socwel.ku.edu/canda, retrieved February 13, 2005.)

Regarding these international developments on spirituality in social work, a clarification is important. All societies in every country have developed social work and social welfare approaches rooted in spirituality long before the formation of professional social work in the United States and elsewhere. For example, the Confucian tradition elaborated philosophy and ideology of social welfare beginning at least 2500 years ago in China. Confucian inspired community based and governmental based social welfare systems existed for many centuries in East Asia (Canda, 2002b; Chung, 2001). What is distinctive in this fourth phase is that professional social workers in various countries are developing various religion-specific, country-specific, and inclusive approaches to spirituality in conjunction with international collaborations.

The topic of spirituality in social work has achieved sufficient acceptance in phase four to appear in mainstream and specialized journals, social work courses, conferences, and textbooks. Thercfore, students, practitioners, researchers, and educators can pursue the topic with far less risk of ostracism than in the past. Faculty and agency supervisors can no longer claim legitimately that there is insufficient knowledge or guidance in our field to address spirituality ethically and competently. Because there are now more than 800 publications within social work on related topics, and many-hundreds in related fields, there is a solid foundation of theory, empitical knowledge, and practice wisdom on which to build. There are nerworks and organizations that reach throughour social work and across disciplines with the United States and around the world so that tremendous mutual learning and synergy can occux, as long as these interactions are guided by values of mutual respect, equity, and collaboration.

All of this is not to imply that the social work profession generally has advanced very far in understanding, appreciation, and skill regarding spiritual diversity. Many social workers in the United States and the United Kingdom are not likely very aware of these trends. Regional and national surveys have indicated that most respondents have not received professional education about spirituality although most do appear to be addressing it in practice somehow (e.g. Canda \& Furman, 1999; Furman, Benson, Grimwood, \& Canda, 2004; Sheridan, 2004). I srill occasionally hear from students, practitioners, and researchers that their teachers, supervisors, or colleagues say that there is not much work done on this topic or that they should not consider it. There are allegations and counter-claims that social work systematically oppresses conservative Christian students and points of view (see Hodge, 2002b and letters to the editor in Social Work April 2003). My impression from conversations with colleagues in many other countries is that there has been even 
less attention paid to spirituality in contemporary professional social work outside North America. This impression is supported by articles about spirituality and social work in the United Kingdom, Norway, Australia, and South Korea (Canda \& Canda, 1996; Furman, Benson, Grimwood, \& Canda, 2004; Rice, 2002; Zahl, 2003). Although our profession has established a solid foundation in this field of interest, there is much more to build (Canda, 1998; 2002a; 2003).

Most importantly, we have established ways to reconnect with our roots in spiritual insights while honoring the particularities of religious and nonreligious spiritual perspectives, the commonalities among individuals' and communities' spiritualities, and the usefulness of cooperation within and between peoples throughout the world who identify with diverse spiritual perspectives or who claim no spiritual interests. This developmental transformation is a breakthrough of spiritual insight and action. It is a paradigm shift that transcends rigid boundaries and polarized views. It has gone beyond arguments that social workers should address spiritualiry from a 'one spiritual way is the only right way' or that social workers should not deal with spirituality because it is irrelevant or dangerous.

It is highly likely that these trends of the fourth phase will continue and increase, assuming that human life is nor suddenly and seriously decimated by nuclear war, a meteor strike, or some other calamity. The question is how should the profession of social work engage with these trends. This is the province of prophecy.

\section{PROPHECY}

I believe that there is an extremely important general developmental process that enfolds the various trends of the fourth phase. Creative thinking and acting about spirituality in social work is catalyzing our profession to grow beyond egocentric, ethnocentric, nationalistic, humanocentric and other divisive and parochial views. It is not surprising that professional social work in the United States would have been biased toward Eurocentric, parriarchal, nation-centered, Judeo-Christian and human privileged perspectives during most of the $20^{\text {th }}$ century because that was the conditioning cultural context. As Coates (2003) pointed out, professional social work formed within a modernist set of world view assumptions. However, it is remarkable and praiseworthy that the profession kept moving in the direction of inclusion, caring and justice from its inception-moving into wider and deeper understandings of human diversity and ideals of well-being for all people.

On a pracrical level, the development of American social work to include and transcend bounded perspectives is shaped by a larger worldwide transformation of consciousness, culture, and technology. Given that virtually all people and all parts of the world are now actually or potentially in contact, through political and economic institutions, mass communications, movement of populations, and the internet, social work in any country can no longer rest on parochial views. For better and worse, globalization is happening. This includes the interconnection of social workers, social welfare organizations, informal community support systems, and spiritual perspectives around the world. As social workers outside the USA are also influenced by these world trends, they too are reaching out in expanded worldview and collaborations.

This developmental process is not just a reaction to social environmental pressures. Many social workers, including founders such as Jane Addams, had and continue to have 
creative and proactive spiritual visions of welfare and justice. We keep challenging ourselves to expand our understanding, compassion, and justice activism to ever widening circles of at-one-time unacknowledged and marginalized groups. This is a spiritual growth process toward a professional consciousness and culture of inclusion that appreciates diversity while including and transcending the spiritual insights of particular individuals, groups, communities, and religions. This developmental process helps us to respect spiritual beliefs and experiences in particular contexts. It also helps us to communicate, collaborate, and cohabitate in a murually beneficial way. As the profession conveys expanded consciousness to students, it challenges them to expand their personal views toward spiritually sensitive and culturally competent ways of doing social work (Canda \& Furman, 1999; Raines, 2004; Rey, 1997).

However, continued development toward greater inclusion within the profession in general or within the movement toward spiritual sensitivity is not automatic or guaranteed. This furure will be a matter of decision, action, and persevcrance along each moment of the present. All the trends of phase four need to continue for a long time if spirituality is to become pervasively understood and addressed in social work around the world. Dangers of religiously and ideologically based intolerance, divisiveness, and competition for privilege can derail or corrupt any of these trends.

However, if these trends conrinue at the present rate, I expect that there will be wellestablished movements of appreciation for spiritual diversity in social work on every continent within 20 years and that these will be interconnected thoroughly. I believe this development is crucial to meet the challenges of counter trends in the USA and around the world of imperialism, genocide, sexism, religious persecution, environmental racism, homophobia, and other forms of alienation and oppression (Coares, 2003).

\section{CONCLUSION: EVEN FARTHER REACHES}

Perusal of the extensive bibliography on spiritual diversity in social work shows some gaps and limitations of current scholarship that should be addressed (Canda, Nakashima, Burgess, Russel \& Barfield, 2003). We should expand research about the range of spiritual perspectives within the USA and around the world. For example, there is still little published on Asian originated religions, First Nations religions, Islam, ecophilosophy, and transpersonal perspectives. Wicea, Neo-paganism, and alternative or new religious movements are barely addressed. Even within the spiritual perspectives considered so far in social work literature, greater depth and breadth of knowledge is needed, especially through ethnographic and participatory action research methods that give rich and detailed accounts of people's experience of spirituality in their own terms and contexts.

More information and guidance are needed with regard to spiritually sensitive practice with specific cultural groups and in particular national contexts. Much more work on international and cross-cultural perspectives for social action and social development is crucial. Work on specific fields of social work practice needs much more expansion both through new studies by social workers and by drawing on rapidly increasing studies in other disciplines. For example, the adult mental health field has had most attention so far, but even that has not yet used much of the current work on spirituality in psychology of religions, transpersonal psychotherapy, and the consumer driven mental health recovery 
movement. Fields of gerontology, addicrions, hospice, and health are good examples of recent rapid growth. But there is very little regarding school social work, agency administration, community organizing, macro social development, social policy, and international social work. There has been very little published in social work about issues of gender, disability, and sexual orientation connected to spirituality. There is very little published on addressing spirituality with children in social work.

Generally, we need to know more about what social workers actually do in practice (at all system levels and in all fields), what works well, and what spiritually focused helping approaches we could learn from helping professionals and community based religious helpers and healers beyond social work. Most studies of how social workers address spirituality in practice have been concentrated on clinicians through surveys, small-scale anecdotal reflections, and relatively brief interviews. While we need more of these, we also need greater artention to mezzo and macro levels of practice. We should engage in more direct observational and field studies with prolonged engagement for greater depth and realistic portrayal, mixed methods studies to join breadth and depth perspectives, and quasi-experimental and experimental designs to examine efficacy. We need to utilize more transpersonal research methods geared to the explorarion of consciousness, alternative and complementary healing modalities, and spiritual qualities of group dynamics in collective action for justice (e.g. Braud \& Anderson, 1998). And we can reach vision for inquiry, education, and practice even farther.

One of the most far-reaching visions of spirituality in social work is that shared by deep ecologists and ecofeminists. They call for an expansion of social work's person-environment perspective and social justice action to encompass all people, beings, ecosystems, and the entire Earth. However, even these do not go far enough-- they have nor gone beyond concern with the Earth.

Some readers might be thinking that Earth wide consciousness and concern is already going far if not too far for social work. But I believe that our profession has quite a way to go if we are to catch up to the activities of national and international space agencies, military operations, communication technology companies, and new private entrepreneurial space tourism companies. Human beings have already traveled beyond the Earth's atmosphere, walked on the moon, orbited surveillance and communication satellires, worked roward orbiting military weapons, lived together in a space station, landed rovers on Mars, and sent probes beyond the solar system. There are long range plans to colonize other planets. Perhaps social workers could encourage ecologically sustainable models of human interactions both within and beyond the Earth. We could advocate for distribution of resulting benefits in an equitable manner across nations and socio-economic classes; genuine respect for any sentient beings we may encounter; and appreciation for the human-Earth-cosmos interconnection wherever we are. Granted there are urgent and seemingly overwhelming needs for more conventional feer-on-the-ground social work in every country. All I am suggesting is that we should keep our minds open, stay alert for ever expanding arenas to advance well-being and justice, and do what we can. Otherwise, at some point, we are likely to be very badly surprised.

Another far-reaching vision about spirituality in social work goes to the transpersonal and nonphysical qualities of reality: subjectivity, consciousness, spirit, immanent sacred- 
ness and transcendent divinity. For example, various transpersonal theories and religious traditions explore altered or expanded states and flows of consciousness (as in trance, prayer, meditation, hypnotism). They posit nonphysical aspects of humans, other beings, and the universe as a whole, such as souls; plant and animal spirits; spirits of mountains, waters, lands, skies, stars, and underworlds; angels, ancestors, ghosts, and deceased saints and sages; life force energies (such as kundalini or chi); cosmic principles (such as Tao); and the ultimate nature of reality itself (such as God, Buddha Nature, Brahman, Tao, unitary consciousness). Some nonphysical entities are considered to be intrinsically good and helpful. Others are considered to be mischievous, ambiguous, or outright evil.

I do not believe that it is the proper domain of professional social work to proselytize particular metaphysical beliefs. However, given that most people in the world believe in nonphysical spiritual qualities and that some clients believe them to be crucially involved in their lives and goals, we should further explore their role, if relevant to clients, in helping or hindering individuals and communities. We need to become more familiar with such issues as differential assessment of spiritual crises from psychopathology; the way people experience the presence of God, angels, and helping spirits in recovery and resilience; how beliefs and experiences regarding harmful, imbalanced, or evil spiritual forces affect them; and how beliefs of communities about divine will, fate, cosmic evolution, and eschatology may shape views of personal situation, social policy and social justice. Social work may contribute to people's experiences of well-being in relation with their own souls, the spirits around them, and Ultimate Reality itself, however they understand these spiritual phenomena.

As the farther reaches of human nurture extend, we are likely to discover more amazing possibilities for spirituality in social work. If we pursue the trends of the fourth phase, perhaps spirituality will no longer be viewed just as a special interest, but rather as the true heart of helping. Then we will have made a significant leap into a fifth phase or beyond.

\section{References}

Banerjee, M. M. (1997). Strengths despite constraints: Memoirs of research in a slun in Calcutta. Reflections: Natratives of Professional Helping, 3(3), 36-45.

Besthorn, F. H. \& Canda, E. R. (2002). Revisioning environment: Deep ecology for social work education. Journal of Teaching in Social Work, 22(1/2), 79-101.

Brandon, D. (1976). Zen in the art of helping. New York: Delta/Seymour Lawrence.

Braud, W. \& Anderson, R. (1998). Transpersonal reseatch methods for the social sciences. Thousand Oaks, CA: Sage.

Bullis, R. K. (1996). Spirituality in social work practice. Washington, DC: Taylor \& Francis.

Canda, E. R. (1988). Conceptualizing spirituality for social work: Insights from diverse perspectives. Social Thought, 14(1), 30-46.

Canda, E. R. (1997). Spirituality, In R. L. Edwards (Ed--in-Chief). Encyclopediat of social work (19 ${ }^{\text {th }}$ ed., Suppl., pp. 299-309). Washington, DC: NASW Press.

Canda, E. R. (1998). Afterword: Linking spirituality and social work: Five themes for innovation. In E. R. Canda (Ed.). Spirttuality in social work: New directions. (pp. 97-106). New York; Hawordh Press. 
Canda, E. R. (2002a). A world wide view on spirituality and social work: Reflections from the USA experience and suggestions for internationalization. Currents: New Scholarship in the Human Services [on-line serial]. Available: http:/fsw.ucalgary,ca/currents/articles/articles/Candal/ canda_main.hem

Canda, E, R. (2002b). Toward spiritually sensitive social work scholarship: Insights from classical Confucianism. Electronic joumal of Social Work, 1(1), article 2 [on-line serial]. Available: www. ejsw.net/LsueViewl.asp

Canda, E. R. (2003). Heed your calling and follow it far: Suggestions for authors who write about spirituality or other innovations for social work. Families in Society, 84(1), 80-85.

Canda, E. R. \& Canda, H. J. (1996). Korean spiritual philosophies of human service: Current state and prospecrs. Social Development lssues, 18(3), 53-70.

Canda, E. R. \& Furman, L. D. (1999). Spiritual diversity in social work practice: The heart of helping. New York: Free Press.

Canda, E. R. Nakashima, M., Burgess, V. L., Russel, R., \& Barfield, S. T. (2003). Spiritual diversity and social work: A comprehensive bibliography with annotations (second ed.). Alexandria, VA: Council on Social Work Education.

Canda, E. R. \& Smith. E. D. (Eds.). (2001). Transpersonal perspectives on spirituality in social work. New York: Haworth Press.

Chung, D. K. (2001). Confucianism. In M. Van Hook, B. Hugen, \& M. Aguilar (Eds.), Spirituality within religiows traditions in social work prattice (pp. 73-97). Pacific Grove, CA: Brooks/Cole.

Cnaan, R. A. (with Wineburg, R. J. \& Boddie, S. C.). (1999). The newer deal: Social work and religion in partnership. New York: Columbia University Press.

Coates, ]. (2003). Ecology and social work: Toward a new paradigm, Black Point, Nova Scotia, Canada: Fernwood Publishing.

Cowley, A. (1996). Transpersonal social work. In F J. Tutner (Ed.), Social work treatment: Interlocking theoretical approaches (4th ed, pp. 663-698). New York: Free Press.

Ellor, J. W., Netting, F. E., \& Thibault, J. M. (1999). Religions and spiritual aspects of buman service prattice. Columbia, SC: University of South Carolina.

Furman, L. D., Benson, P. W., Grimwood, C, \& Canda, E. R. (2004). Religion and spirituality in social work education and direct practice ar the millennium: A survey of UK social workers. British Joumal of Social Work, 34,767-792.

Gibelman M. \& Gelman, S. R. (2003). The promise of faith-based social services: Perception versus reality. Social Thought: Joumal of Religion in the Human Services, 22(1), 5-23.

Hodge, D. R. (2000). Spirituality: Towards a theoretical framework. Social Thought, 19(4), 1-20.

Hodge, D. R. (2002a). Conceptualizing spirituality in social work: How the metaphysical beliefs of social workers may foster bias toward theistic consumers. Social 7hought, 21(1), 39-61.

Hodge, D. R. (2002b). Does social wotk oppress Evangelical Christians? A "New Class" analysis of sociery and social work. Social Work, 47(4), 401-414.

Joseph, M. V. (1987). The religious and spititual aspects of social work practice: A neglected dimension of social work. Social Thought, 13(1), 12-23.

Loewenberg, F. M. (1988). Religion and social work practice in contemporaty American society. New York: Columbia University Press.

Martin, E. D. \& Martin, M. M. (2002). Spirituality and the Black belping tradition in social work. Washington, DC: NASW Press. 
Maslow, A. H. (1969). The farther reaches of human nature Joumal of Transpersonal Pychologn $1(1), 1-9$.

Meinert, R. G., Pardeck, J. T., \& Murphy, J. W. (Eds). (1998). Postmodernism, religion and the future of social work. New York: Haworth Press.

Nash, M. \& Stewart, B. (Eds.)., (2002). Spirituality and social care: Contributing to personal and community uell-being. London: Jessica Kingsley Publishers.

Nolson-Becker, H. B. (2003). Practical philosophies: Interpretations of religion and spirituality by African American and European American elders. Joumd of Religious Gernntology 14(2/3), 85-99.

Patel, N., Naik, D., \& Humphreys, B (Eds.). (1997). Visions of reality: Religion and ethnicity in social work. London: Central Council for Education and Training in Social Work.

Praglin, L. J. (2004). Spirituality, religion, and social work: An effort towards interdisciplinary conversation. Journal of Religion of Spirituality in Socinl Work: Social Thought, 23(4), 67-84.

Raines, J. C. (2004). Emotional themes in cross-faith encounters among MSW students: A qualitative exploration. Joumal of Religion of Spirituality in Social Work: Social Thought, 23(3), 109 125.

Rey, L. D. (1997). Religion as invisible culture: Knowing about and knowing with. Jotmal of Fam* ily Sorial Work, 2(2), 159-177.

Rice, S. (2002). Magic happens: Revisiting the spirituality and social work debate. Australian Sociat Work, 55(4), 303-312.

Robbins, S. P. Chatterjee, P, \& Canda, E. R. (1998). Contemponary buman behavior theory: A critical perspective for social work. Boston: Allyn and Bacon.

Russel, R. (1998). Spirituality and religion in graduate social work education. In E. R. Canda (Ed.), Spirituality in social work: New directions (pp. 15-29). New York: Haworth Press.

Sheridan, M. J., Wilmer, C. M.* \& Archeson, L. (1994), Inclusion of content on religion and spirituality in the social work curriculum: A study of faculty views. Joumal of Social Work Education, $30(3), 363-376$.

Sheridan, M. J. (2004). Predicting the use of spiritually-derived interventions in social work practice: A survey of practitioners. Journal of Religion and Spirituality in Social Work: Social Thought, 23(4), 5-25.

Siporin, M. (1985). Current social work perspectives on clinical practice. Clinical Social Work Journal, $13(3), 198-217$.

Spencer, S. (1956). Religion and social work, Soctal Work, 1(3), 19-26.

Tirrito, T. \& Cascio, T. (Eds.)., (2003). Religious organizations in community services. New York: Springer Publishing Company.

Towle, C. (1965). Conmon buman needs (rev. ed.). Washington, DC: NASW Press.

Van Hook, M., Hugen, B., \& Aguilar, M. (Eds.). (2001). Spirituality within religious traditions in socidl work practice. Pacific Grove, CA: Brooks/Cole.

Wilber, K. (1998). The marriage of sense and soul: integrating science and religion. New York: Broadway Books.

Wineburg, B. (2001). A limited partnership: The politics of religion, welfare, and social service. New York: Columbia Universiry Press.

Zahl, M. A. (2003). Spiritualiry and social work: A Norwegian reflection. Soctal Thought: Joumal of Religion in the Social Services, $22(1), 77-90$. 


\section{Author's Note}

Address correspondence to: Edward R. Canda, Ph.D., Professor \& Director of the Ph.D. Program in Social Work, University of Kansas, School of Social Welfare, Twente Hall, 1545 Lilac Lane, Lawrence, Kansas 66044-3184. e-mail: edc@ku.edu. 